\title{
Study Results of University Students in the Context of Experiencing Positive Emotions, Satisfaction and Happiness
}

\author{
https://doi.org/10.3991/ijet.v14i23.10882 \\ Martin Malcik, Miroslava Miklosikova $(\bowtie)$ \\ VSB - Technical University of Ostrava, Ostrava, Czech Republic \\ miroslava miklosikova@vsb.cz
}

\begin{abstract}
An optimal motivation for learning is one of the fundamental prerequisites for study success, it is therefore understandable that experts are still looking for additional ways to positively influence university students in this field. One option is the coherent and deliberate use of the close interdependence of motivational and emotional processes. In our reflections, we assume that the low motivation level of university students to learn can be caused by their dissatisfaction with certain areas of their lives. The emotions that they experience may prevent them from experiencing the enjoyment of learning, negatively influence attention, concentration and will, which reflects in their lack of interest and even indifference to learning activities and consequently in deterioration of their learning outcomes. To find out how the students of the VSB - Technical University of Ostrava are satisfied with selected areas of their lives, we presented them with a series of ten consecutive stimuli (one stimulus $=$ a pictogram and a descriptive word) that represented the domains of health - interpersonal relationships - studies - finances personality characteristics. During the time the student followed the given stimuli, we measured their galvanic skin response (GSR) and in this manner followed the physiological manifestations of their emotions. After completing the measurement, the student completed a non-anonymous questionnaire in which they were required to comment on the quality of the emotion they felt during each stimulus. We compared the obtained data with the study success and verified potential dependencies.
\end{abstract}

Keywords-Motivation, emotion, feeling of satisfaction, happiness, university student, study results.

\section{Introduction}

The experts do not agree on a uniform definition of motivation. Among the most well-known theories are Maslow's hierarchy of needs, Herzberg's two-factor theory, Vroom's expectancy theory, Adam's equity theory, Skinner's theory of positive reinforcement, McClelland's need theory, etc. In the broadest sense, motivation is 
understood as a sum of factors that elicit, regulate and maintain the human activity that leads to a particular goal.

Maslow [1] explained motivation through (not) satisfying needs. He created a hierarchy of needs in which, besides physiological and psychological needs, also cognitive needs play their role. These include the need for education, the desire for knowledge, the need to deepen one's intellectual abilities and to understand the world.

As far as emotions are concerned, not even they are defined uniformly. Some theorists consider them to be irrational and disturbing psychological phenomena, others attribute crucial importance to them in a person's life. Zimmer [2] argues that feelings and intentionality create a nucleus of the human nature and are not entirely irrational because they arm people with wishes and joys which shape some of their actions. Nakonečný [3] considers emotions to be mentally and socially-designed processes that involve subjective experiences of pleasure and dislike, accompanied by physiological changes (changes in heart rate, change in breathing rate, etc.), motor symptoms (mimics, gestures) and changes in alertness and focus. An important source of new findings is neuropsychological knowledge, which is facilitated by modern imaging techniques such as emission tomography, magnetoencephalography, functional magnetic resonance imaging and others [4].

Theoreticians are neither united in their views of the relationship between motivation and emotions. Leeper [5] sees a continuum between emotions and motivation and claims that emotions can be both activating and deactivating. McClelland [6] considers that the key aspect of motivation is affective excitement, with positive emotions associated with the emergence of desire and negative emotions associated with aversion. The need resulting from this creates motivation. SchmidtAtzert [7] notes that emotions affect the whole sphere of the mind including motivation. Nakonečný [8] argues that the basic element of learning is solidification, the essence of which consists of rewards and punishments, which can be understood as pleasant and unpleasant experiences, that is, as emotions. He claims that emotions decide what the subject learns and what they do not, through desire or aversion. Emotions are, according to the author, the essence of motivation, in which it is always about either avoiding the unpleasant or achieving the pleasant. Here, the link between motivation and emotions is evident.

\subsection{Emotive, cognitive and motivational processes}

While cognitive processes process the instrumental meaning of information, emotional processes express the subjective meaning of emotions, including their subjective value. The evaluation process leads to the recognition of certain values which can be in the positive sense regarded as the subjective concept of good. A person may consider the following values as good for them - freedom, health, education, learning, slacking, etc., and achieving and maintaining them is motivating for that person. Therefore, if a learner perceives learning and education as a process of positive value, then they can better motivate themselves.

Emotional processes are commonly divided into lower, higher, ethical, aesthetic, sthenic, asthenic and intellectual, but also into pleasant and unpleasant. The pleasant- 
unpleasant division, however, cannot be understood mechanically. A student, whose goal is to experience a good feeling when obtaining a Master's degree, is willing to take on many unpleasant activities, so the end goals and not the partial goals are decisive. On the other hand, what a student sees as pleasant does not necessarily benefit them (e.g. alcohol, drugs, procrastination, etc.). Moreover, the situation is complicated by the fact that an initially pleasant stimulus may become unpleasant in time or by an increase in its intensity; or an initially unpleasant stimulus may become even more unpleasant by the same token. Experts, e.g. Guillaume [9]1953) also bring up the dependence of whether something is pleasant or unpleasant on the situational context, mood, and the momentary mental state of an individual.

In connection with education and learning, on the one hand, and emotions, on the other, the evolutionary higher sentiments are mentioned, whose sources are ethical, aesthetic and intellectual values, the latter being related to the value of truth and knowledge of a particular individual. All higher sentiments are judgment experiences, and their elementary form consists of curiosity and the pleasure of discovering and finding order [10]. If an individual, a university student in our case, is to understand and appreciate the value of education and self-motivate oneself to learn, they need to become emotionally mature. If they are not sufficiently mature in this respect, then they are more dependent on external motivation, and at this point, it depends more on the didactic competence and personality traits of the university educator.

The close link between emotional and motivational processes also stems from the fact that motivation processes are experienced as efforts that are accompanied by more or less clear goal awareness [3]. In this context, Šingarov [11] argues that behaviour is a complex of emotional and intellectual components, but its psychic cause is emotional, which explains why an individual acts, but also why they learn.

In this context, we would like to mention the term "emotional intelligence". Emotional intelligence is defined as the ability to perceive and understand one's emotions, and as the deftness to use them in cognitive and other activities, and in dealing with people. Goleman [12] argues that emotional intelligence has the greater significance in a person's life the more complex activities they need to perform in their profession. And learning, in our opinion, is certainly a complex activity.

The degree of motivation of an individual to learn can also be related to the general sense of satisfaction. The motivation of a satisfied and happy student to learn can be completely different to when they are dissatisfied and unhappy.

\subsection{Sense of satisfaction, happiness and motivation}

Satisfaction is a pleasant feeling in which emotions play a crucial role, and their frequency is more important than their intensity [13]. One can, however, be happy with their life even when they are not enjoying a happy period. Křivohlavý [14] writes that although the feeling of happiness is a subjective affair, it can be argued that mostly people feel happy in functional interpersonal relationships, when they perform meaningful activities and professions, while staying in the wild, when they enjoy good health, when they manage to overcome a serious problem ... The feeling of happiness is, according to the author, in a close relation to the personal values scale 
and goals of the individual and has an emotional and a cognitive aspect. Regarding the cognitive aspect, Diener and Lucas [15] claim that some individuals can recognize and process positive messages faster than the negative ones, and believe that the amount of positive information is larger, and they also use more positive words and phrases. These people also positively evaluate their past life situations. Carver and Scheier [16] are convinced that an individual's satisfaction and feelings of happiness are influenced by all their cognitive constructs (concepts, plans, beliefs...) because the individual uses them to relate to the world and change it, and the surrounding world has a feedback effect on their perception. That is why, for example, the optimist is able to perceive more positive events and also to expect more of them in the future.

The genetic background of an individual and the level of their education also add to happiness and contentment. However, the correlation between happiness and education is not unambiguous. In economically poorer countries, people with higher education are happier and more content than people in richer countries, which is often justified by the fact that in economically rich countries, higher education is not uncommon, so it is not the source of that many subjective positive feelings [17]. The question arises then: Are the non-motivated university students, to a certain extent, the result of a well-prospering economy and overly easy access to education?

We believe that certain type of personality - positive-minded individuals [18], who are satisfied with their lives are more emotionally balanced, better able to concentrate on cognitive activities, it is easier for them to overcome obstacles in learning, and also they are better able to endure when the focus is on performance and during demanding exam periods. We have been testing this hypothesis through research.

\section{Research Goal}

The aim of the research was to find out whether the students of VSB - Technical University of Ostrava, who are more satisfied with their lives, achieve better study results, and to find out which areas of life are most problematic for students in general.

\section{Research Method and Procedure}

The research took place at VSB -Technical University of Ostrava from $28^{\text {th }}$ May to $30^{\text {th }}$ May 2018. It was attended by 30 students -19 men and 11 women aged 21-25.

First of all, we presented to the students the stimuli from the domains of health interpersonal relations - study - finances - features of their own personality; during the presentation, we measured their GSR, which was an indicator of the physiological manifestations of their emotions, specifically their quality. The data we obtained were paired with data from a non-anonymous questionnaire, which was also focused on the individual domains - the students were required to state which stimulus (domain) gave them a positive or negative feeling. The data we obtained were compared with the average of their study results - study success of the students. 


\subsection{Biofeedback and physiological manifestations of emotions}

According to experts, emotions pervade the whole psyche and are in close contact with cognitive processes, motivation, value system and physical health.

The connectedness of emotions with body reactions has always been in the centre of attention. Emotions, with regard to changes they cause, moved to the forefront of physiological research [19]. James [20] is considered to be the founder of the physiological approach to emotions and he stated that physiological changes come right after the perception of an exciting event which people experience and he described feeling as an emotion. His opinion on the given subject is still influential.

\subsection{The Sensetio measuring device)}

The Sensetio measuring device is a bracelet connecting up to a computer through a Bluetooth USB interface. For recording and evaluation, the Sensetio software is used, which enables to export measured data in a csv format. We can use a sensor of skin conductivity, which uses two electrodes attached to fingertips (see Picture 1) and works as if they were terminals of a resistor (skin resistance). This resistance is one branch of a voltage divider. The voltage thus captured is then filtered and amplified and then evaluated through a compensation algorithm by the Sensetio measuring system.

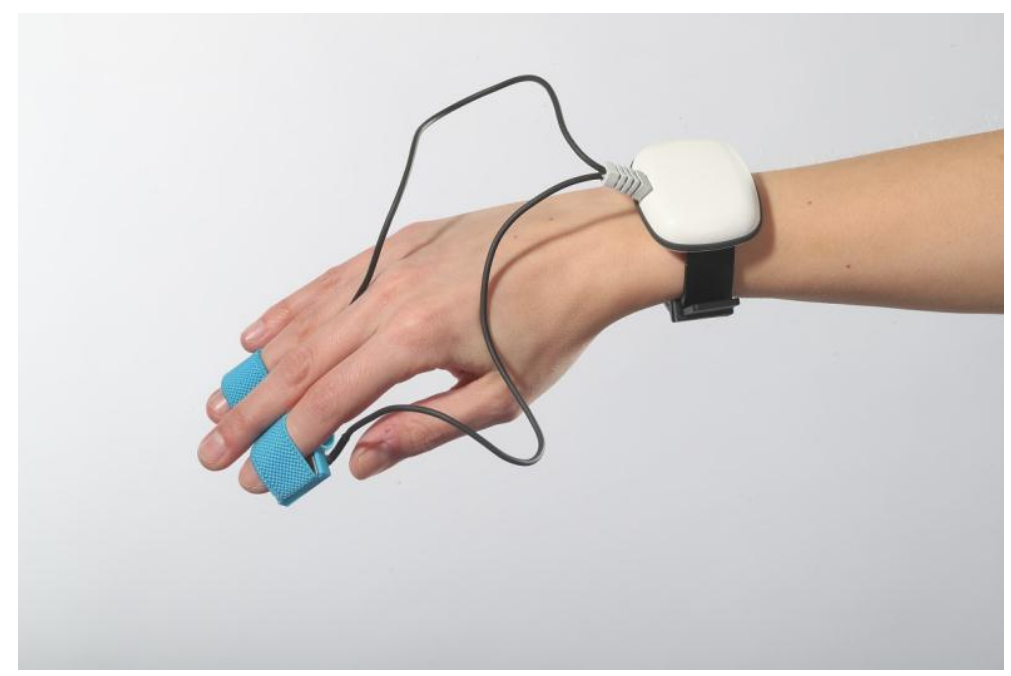

Fig. 1. Position of GSR sensors Sensetio on respondent's hand

\section{$4 \quad$ Research Results}

To give an idea of how we worked with the data obtained through the research, we will present the conclusions we reached with four of our respondents. 
Respondent 1, a student of the second year of bachelor studies with a study average of 2.16, aged 22, identified the following areas as problematic in the questionnaire: exercise (health domain), communication with a sibling and parents (relationships domain), lack of interest in studies and procrastination (study domain), his susceptibility to fear, anxiety, and depression (the domain of personality traits). When comparing the respondent's testimony with the character and the fluctuations of the GSR curve, we find that they correlate to a large extent. This respondent mentioned several areas where he currently does not feel comfortable (satisfied), which is reflected in the values of his GSR. The question remains whether his study results would improve if he were more satisfied in the given areas of life.

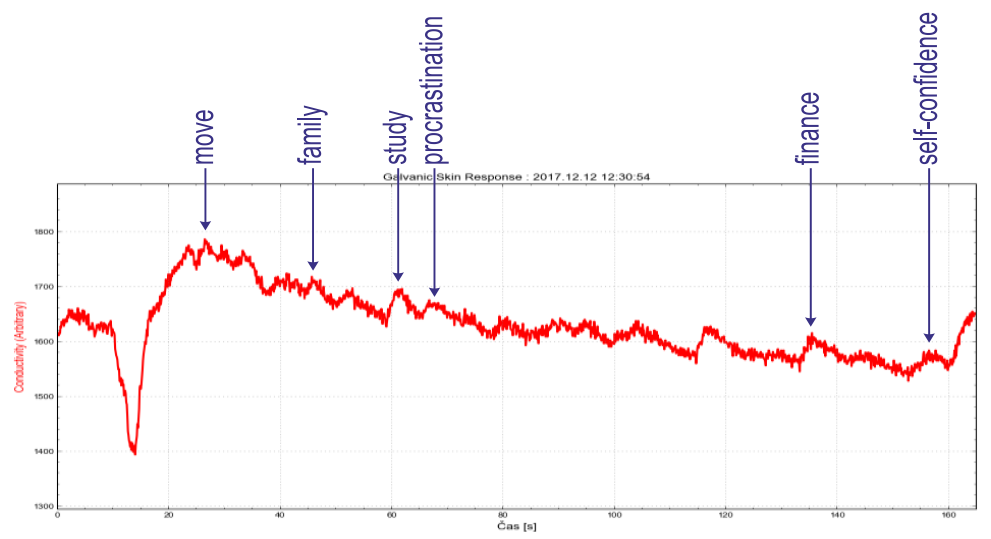

Fig. 2. Sequence of the GSR values of Respondent 1

Respondent 2, a student of the second year of bachelor studies with a study average of 1.87 , aged 22, identified the following areas as problematic in the questionnaire: illness, medicine, doctor, death (the domain of health), her susceptibility to fear and anxiety (personality traits domain). From the respondent's testimony, we could conclude that the area of health is problematic for her, and she observes a certain imbalance, a tendency to experience fears and anxieties. This may be related to the nature of her self-confidence. She identifies herself as a choleric personality in the questionnaire who responds emotionally quickly. This was also reflected in the nature of her GSR curve - at the beginning of the experiment, her excitement grew and remained on a certain level throughout the measurement. This student has the least number of problematic domains, a fairly balanced curve and the best study average. 


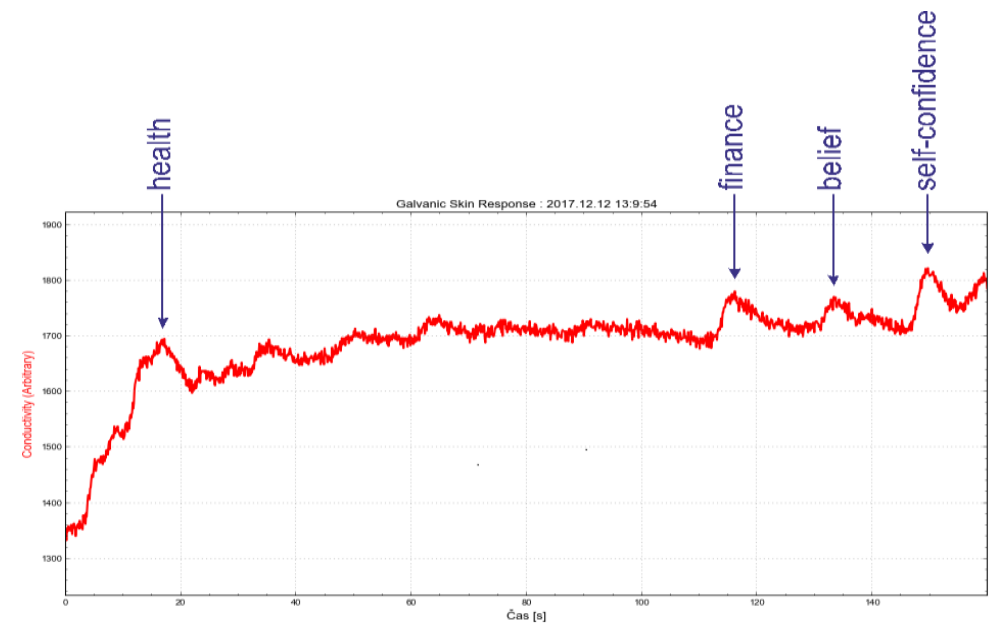

Fig. 3. Sequence of the GSR values of Respondent 2

Respondent 3, a student of the third year of bachelor studies with a study average of 2.00, aged 23, identified in the questionnaire the following areas as problematic: illness, medication, obesity (health domain), communication with parents and friends (relationships domain), postponement of study duties (study domain), debt (finances domain), her propensity to fear and anxiety, and fear when thinking about life (personality traits domain). This may be linked to the extent of her self-confidence, which she also identified as problematic. Her self-perception and self-assessment are fairly accurately reflected in the character of the GSR curve, including its high value at the beginning of the measurement - she said she was "awfully" nervous before the measurements. As far as the study average is concerned - considering the number of areas the student perceives as problematic, the study results are not of bad quality.

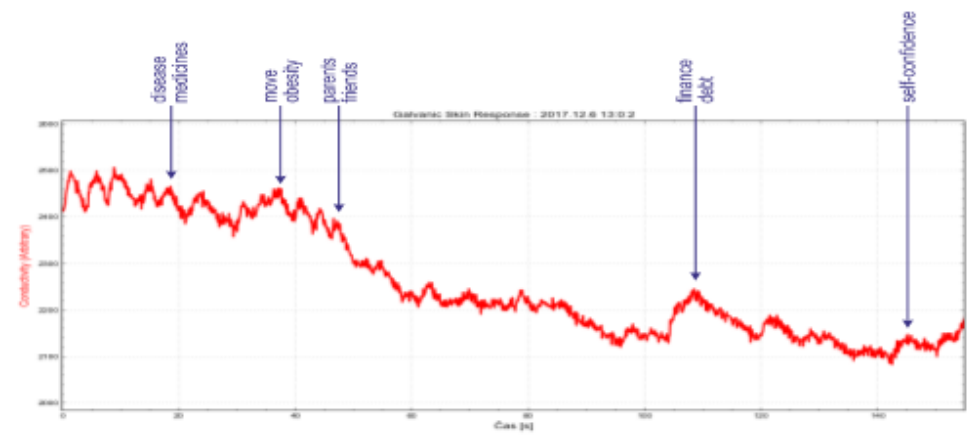

Fig. 4. Sequence of the GSR values of Respondent 3

Respondent 4, a student of the third year of bachelor studies with a study average of 2.13, at the age of 23, identified in the questionnaire for himself the following areas as problematic: illness, medication, death, obesity (domain of health), friends (domain 
of relations), uninteresting study, postponement of study duties (study domain), lack of finances (finance domain). The student has rated himself as a person who is worried, anxious and does not believe in himself too much. Comparing his selfesteem and self-assessment with the GSR curve, we can say that it reflects his views, including the fact that the student was severely stressed before the measurement, subsequently, his nervousness subsided. This third-year student has more areas that he perceives as problematic, but his study average is far from being the worst.

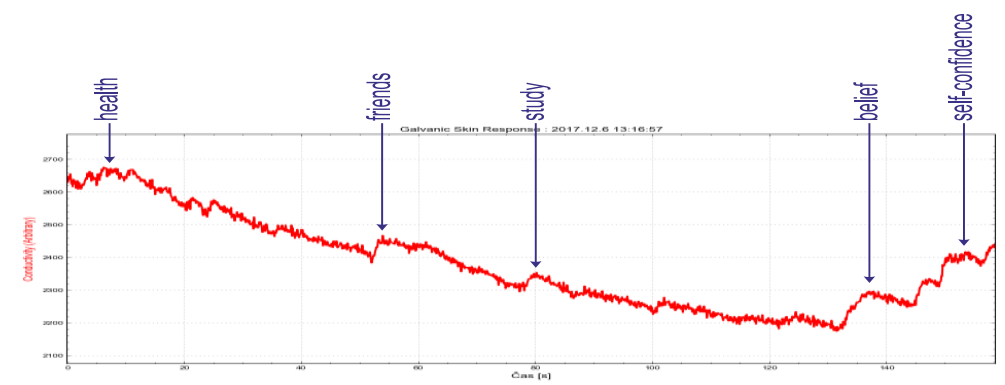

Fig. 5. Sequence of the GSR values of Respondent 4

\subsection{General evaluation of the measured GSR values}

The data we obtained by measuring the GSR of thirty respondents were evaluated as follows:

Sixteen respondents reacted with an increasing GSR to the "health" stimulus and marked the felt feeling as unpleasant during stimulus perception. In all cases, the respondents indicated unpleasant feelings when they followed the "disease" and "medication" stimuli, 7 respondents indicated the "death" stimulus as an unpleasant stimulus. We can say that students are well aware of the importance of health and maybe do not put enough care into it.

Seventeen respondents reacted with an increase of the GSR to the "motion" stimulus and marked the feeling they felt as unpleasant. And because all of them identified "obesity" as a problematic area in the questionnaire, they are likely realizing that movement is important and that they devote little time to it at the expense of passive activities. The objective answer could be obtained by a more detailed research, for example using the standardized interview method.

Twenty out of 30 respondents responded with increasing GSR values to the "family" stimulus, and the perceived feeling during stimulus perception they marked as unpleasant. Probably these indicate communication breakdowns, different opinions between parents and students about studies or other activities, which is to some extent normal.

Eighteen respondents reacted with raising GSR to the "friends" stimulus and experienced an uncomfortable feeling during stimulus perception. Given the negative nature of the feelings experienced during this stimulus, it could be speculated that friendly relationships currently do not work or do not work at all, or that students miss their friends or do not have friends. This question would require independent research. 


\section{Conclusion}

The aim of the research was to find out whether the students of VSB - Technical University of Ostrava who are more satisfied with their lives achieve better study results, and which areas of life are most problematic for students in general. The research took place at VSB - Technical University of Ostrava from $28^{\text {th }}$ May to $30^{\text {th }}$ May 2018. It was attended by 30 students -19 men and 11 women aged 21-25.

We found out that students perceive health, family and friend relationships, studies, and some of their character traits as the most problematic areas. We were surprised that 18 out of 30 students reported that they often felt fear and anxiety, had a tendency to depression and did not believe in themselves much. As to why, this is a subject of other researches, but the sequence of GSR values of our respondents is an evidence to the truthful nature of these findings.

Regarding the relationship between positive emotions, life satisfaction and study results, we have not found any direct dependency. This is due to a small number of respondents, which means that we need to continue comparing these variables. On the other hand, there may be no interdependence found even with a larger number of respondents, because the relationship between emotions, feelings of happiness and satisfaction on the one hand, and learning success on the other is very complex and complicated. In any case, however, we believe that the positive outline of a student's personality and the adequate amount of problems and challenges they need to deal with, strengthen their personality, contribute to the desired course during studies and can also have a positive impact on study success.

\section{Acknowledgement}

This research was funded by a R\&D project Eta, TL01000299 from budget of Czech Republic.

\section{$7 \quad$ References}

[1] Maslow, A. H. (1970). Motivation and Personality. New York: Harper and Row.

[2] Zimmer, D. E. (1984). Die Vernunft der Gefühle. Usprung, Natur und Sinn der menschlichen Gefühle. München: Amazon.

[3] Nakonečný, M. (2000). Lidské emoce. Praha: Academia.

[4] Malčík, M., Miklošíková, M. (2018). Biofeedback as part of pedagogical selfreflection. In ICETA 2018: 16th IEEE International Conference on Emerging eLearning Technologies and Applications: proceedings: November 15-16, 2018, Starý Smokovec, The High Tatras, Slovakia. Piscataway: IEEE, 2018, s. 341-348. https://doi.org/10.1109/iceta.2018.8572149

[5] Leeper, R. (2012). The motivational theory of emotion. In Stacey, C. L., DeMartino, M. F. Understanding human motivation. London: Waterstones.

[6] McClelland, D. C. (1953). Personality. New York.

[7] Schmidt-Atzert, L. (1996). Lehrbuch der Emotionspsychologie. Stuttgart - Berlin - Köln.

[8] Nakonečný, M. (1998). Základy psychologie. Praha: Academia. 
[9] Guillaume, P. (1953). Manuel de psychologie. Paris.

[10] Blagonaděžinová, L. V. In: Smirnov, A. A., Leontěv, A. N., Rubinštejn, S. L., Těplov, M. B. (1961). Psychologie. Praha.

[11] Šingarov, G. Ch. (1971). Emocii i čuvstva kak forma odraženija dejstvitělnosti. Moskva.

[12] Goleman, D. (1995). Emotional Intelligence: Why it can matter than IQ. New York: Bantam.

[13] Diener, E., Suh. E. M. (2000). Subjective well-being across cultures Cambridge: Press.

[14] Křivohlavý, J. (2013). Psychologie pocitu štěstí. Praha: Grada.

[15] Diener, E., Lucas, R. E. (2008). Subjective emotional well-being. In: Lewis, M., HavilandJones, J. M., Feldman, Barret, L. (2008). Handbook of Emotions (3rd ed.). New York, London.

[16] Carver, Ch. S., Scheier, M. F. (2008). Perspectives on personality. Boston: Allyn and Bacon.

[17] Argyle, M. (1999). Causes and Correlates of happiness. In: Kahneman, D., Diener, E., Schwarz, N. Well-being: the foundations of hedonic psychology. New York: Russel Sage Foundations. https://doi.org/10.1017/s0953820806231972

[18] Malčík, M., Miklošíková, M. (2017). Effect of an Emotional Video on Skin Conductance Response of Respondents in Dependence on Personality Type. Proceedings ICL 2017, Budapest, Hungary, pp. 1160-1164.

[19] Stuchlíková, I. (2007). Základy psychologie emocí, Praha: Portál.

[20] James, W. (1890) Principles of Psychology, New York: Henry Holt.

\section{Autors}

Martin Malcik received his Ph.D. in Applied mathematics and assoc. prof. in applied informatics. He currently works at the VSB - Technical University of Ostrava. He is engaged in utilization of information technologies in aducation and human resources development. He is currently working on utilization of eyetracking for reading and understanding improvement. martin.malcik@vsb.cz

Miroslava Miklosikova received his $\mathrm{PhD}$. degree in Theory of Teaching and Learning of Vocational Subjects and assoc. prof. in Theory of Teaching and Learning of Vocational Subjects. She currently works at the VSB - Technical University of Ostrava. She is engaged in teaching psychology of education and enhancing the creativity of students.

Article submitted 2019-05-17. Resubmitted 2019-09-17. Final acceptance 2019-09-29. Final version published as submitted by the authors. 